\title{
ENVIRONMENTAL POLLUTION BY MERCURY AND RELATED HEALTH CONCERNS: RENOTICE OF A SILENT THREAT
}

\author{
Sara MOSTAFALOU and Mohammad ABDOLLAHI \\ Department of Toxicology and Pharmacology, Faculty of Pharmacy and Pharmaceutical Sciences Research Center, \\ Tehran University of Medical Sciences, Tehran, Iran
}

During the 1950s, while Japanese researchers were seeking for the cause of a strange and fatal neurologic disease spread in Minamata city, it seemed ludicrous that an element located in the period 6 and group 12 of the periodic table would be to blame. Mercury in its organic form, i.e. methyl mercury, was released from the wastewater of a chemical company; bio-accumulated in fish and shellfish, and was subsequently eaten by local inhabitants. Thus, it transformed into an agent for thousands of cases of poisonings that later became known as Minamata disease. Two decades later, another disaster happened in Iraq, where around 1000,000 $t$ of mercury-treated seed grain were mistakenly used for making bread and caused more than 6000 poisonings and 400 deaths (1). Several other stories like this have also been noted elsewhere, but concern regarding this toxic metal has shifted towards its global emission and distribution, which causes it to slowly enter into people's homes, food and water, consequently affecting human health on a much larger scale.

As a naturally occurring element, mercury can be found throughout the environment (soil, water, air) and can exist in three forms: elemental or metallic, inorganic, and organic. This metal is neither created nor degraded but its release into the environment by mankind's manipulations has made it a global pollutant. According to a report by the US Environmental Protection Agency, natural emission from the ocean and volcanic eruptions account for one third of the world's mercury emission, while the remaining two thirds are related to human activity. For instance, mercury is abundantly found in coal, whose burning causes its release into the air. That is why coal-fired power plants are the largest source of mercury emission. Other mercury sources include artisanal and industrial gold mining; wastewater from metal, cement and alkaline factories; waste incineration; and products containing mercury such as linear or compact fluorescent lamps, batteries, electrical devices, paint, pesticides, fertilizers, thermometers, amalgam, pharmaceuticals, and cosmetics (2).

Once released (elemental or inorganic), mercury circulates between the air, soil, and water. Under the effect of certain chemical reactions, elemental mercury can transform into its inorganic form which can later be deposited in particulates and precipitations, ultimately leading to its accumulation in rivers, lakes and streams. Once deposited in water or soil, certain microorganisms can transform it into methyl mercury, a highly toxic and bioaccumulative form, themselves later becoming food for fish and other aquatic organisms. This way, methyl mercury accumulates upwardly in the food chain in fish, fish-eating birds and animals, eventually reaching the general population (3).

Humans are exposed mainly through consuming contaminated fish and shellfish or by inhaling vapours of an elemental form arising from industrial processes, or even from breaking products containing mercury. Low-level exposure through rice consumption by populations from areas with mercury-contaminated water reservoirs has also been suggested (4).

Since its primary mechanism of action involves binding to sulfhydryl groups, mercury can impair the function of any cellular or subcellular structure in the body. The most susceptible targets for mercury are selenoenzymes, particularly thioredoxin; an antioxidant defence system responsible for scavenging reactive 
oxygen species. Therefore, the induction of oxidative stress, as a phenomenon in the very centre of a disease, has essentially been implicated in the toxicity of mercury $(5,6)$. The diversity in toxic effects and target organs is due to the difference in the tissue distribution of each mercury form to which exposure occurs. Elemental and organic forms can easily pass through the blood brain barrier and placenta causing neurologic and neurodevelopmental dysfunction, while inorganic mercury, which lacks this ability, primarily causes the impairment of its main route of exposure, the gastrointestinal tract, as well as the kidneys, where it precipitates (7).

However, mercury toxicity even at low-level exposures has been suspected of causing a wide range of disorders, including neurological and psychological damages manifested by tremor, headache, insomnia, memory loss, polyneuropathy, emotional variation, cognitive dysfunction, birth defects mainly manifested by neurodevelopmental disruption, reproductive disorders, renal and cardiovascular insufficiency, metabolic diseases, immunotoxicity and carcinogenicity $(8,9)$. Regardless of the broad spectrum of mercury toxicities, even more concerning are the frequent misdiagnoses of intoxication caused by their insidious onset and nonspecific symptoms. A common mistake repeatedly made by medical experts during the history of outbreaks of mercury-related illnesses is a delay in recognizing them, which causes an even more disastrous effect (1).
Mercury emission has been especially highlighted on a global scale, since it knows no national or continental border and can be transported thousands of miles due to its long residence time in the atmosphere before being deposited back. The mercury found in arctic wildlife species, far from human activities and emission sources is evidence to this claim. In addition to long-range transport, regional features are also a determinant factor, since there are certain geographic locations where mercury is more efficiently oxidized and deposited $(10,11)$. Mercury emission and deposition is declining in North America and Europe due to recent legislation such as the Mercury Export Ban Act of 2008, Mercury-Containing and Rechargeable Battery Management Act of 1996, Clean Air Act, Clean Water Act, Resource Conservation and Recovery Act (RCRA), and the Safe Drinking Water Act, while it is increasing in Asia, particularly in rapidly developing countries (2). Although China, which is responsible for $25 \%$ of the world's mercury release, has become the largest source of mercury emission (12), other Asian countries such as India, Indonesia, etc., have accounted for more than half of Asia's global mercury emission during the past decade. What is even more unfortunate is the lack of preventive measures and educational programs aimed at mitigating the mercury burden $(13,14)$.

One area where these nations should direct more attention is the proper disposal of numerous mercurycontaining products, a large quantity of which is annually released to the market and living environment.

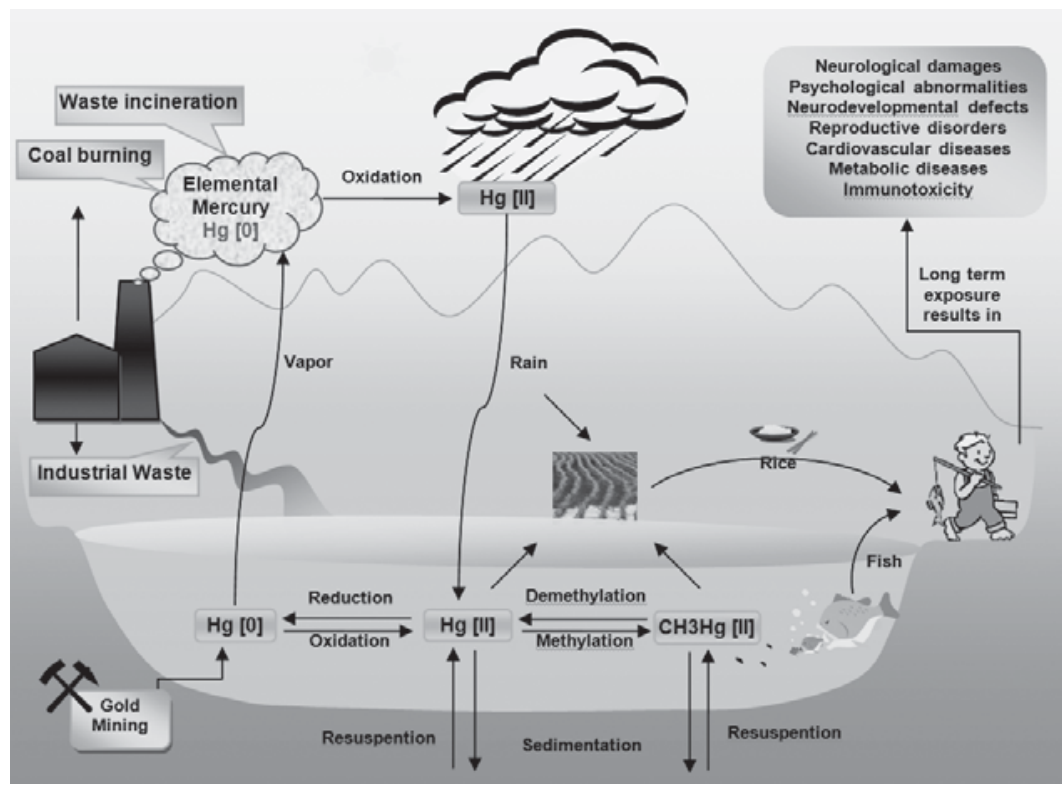

Figure 1 A simplified diagram illustrating the atmospheric emission, circulation, deposition and bioaccumulation of mercury in relation to human exposure and health effects, $\mathrm{Hg}$ [0]: (elemental mercury), $\mathrm{Hg}$ [II]: (inorganic mercury) and $\mathrm{CH}_{3} \mathrm{Hg}$ [II]: (organic mercury). 
Damaging these products during production, transport, marketing, or landfilling, as well as incinerating them, releases mercury into the environment for a period ranging from one week up to several years. Compact fluorescence lamps (CFLs) are among the most widely used mercury-containing products for which different regulations have been set in the US and Europe. Starting with 2007, the US National Electrical Manufacturers Association (NEMA) set a reduction limit for mercury in CFLs, whereas an identical limit had previously been set by the Restriction of Hazardous Substances Directive (RoHS) in the EU (15). In some parts of the world such as the US, Canada, Australia, and Europe, CFLs are defined as products subject to recycling schemes; for instance, through the Waste Electrical and Electronic Equipment Directive (WEEE) in the EU. The Directive makes it illegal to dispose of CFLs by waste sent to landfills; they need to be separately collected by manufacturers for recycling. In fact, these laws try to create a closed-loop system for mercury, prescribing its recovery and reuse in order to reduce emission from municipal solid waste $(16,17)$.

Much more could be said about mercury and the related risks, but one point that should not be ignored is that, during the past century, its hazardous effects have never come as a surprise to environmental researchers; however, the ways through which it permeates into people's lives and negatively affects public health most frequently have. The rapid progress of technology in developing countries has made mercury emission inevitable, but given the potential of even a low-level exposure in afflicting human health through generations, it needs to be treated as a silent threat that requires preventive measures. Governmental and non-governmental organizations must make a turn in their approach and apply informative and educational programs, as well as make pragmatic decisions aimed at reducing mercury burden both nationally and internationally.

\section{Acknowledgement}

The authors wish to thank the Iran National Science Fundation (INSF) for assistance in supporting the postdoc program of the first author.

\section{REFERENCES}

1. Grandjean P, Satoh H, Murata K, Eto K. Adverse effects of methylmercury: environmental health research implications. Environ Health Perspect 2010;118:1137-45.

2. U.S. Environmental Protection Agency. Mercury [displayed 15 January 2013]. Available at http://www.epa.gov/hg/index. html
3. Clarkson TW, Magos L. The toxicology of mercury and its chemical compounds. Crit Rev Toxicol 2006;36:609-62.

4. Li P, Feng X, Qiu G. Methylmercury exposure and health effects from rice and fish consumption: a review. Int J Environ Res Public Health 2010;7:2666-91.

5. Bernhoft RA. Mercury toxicity and treatment: a review of the literature. J Environ Public Health 2012;2012:460508. doi: $10.1155 / 2012 / 460508$

6. Farina M, Rocha JB, Aschner M. Mechanisms of methylmercury-induced neurotoxicity: evidence from experimental studies. Life Sci 2011;89:555-63.

7. Broussard L, Hammett-Stabler CA, Winecker RE, RoperoMiller JD. The toxicology of mercury. Lab Med 2002;33:61425.

8. Karagas MR, Choi AL, Oken E, Horvat M, Schoeny R, Kamai E, Cowell W, Grandjean P, Korrick S. Evidence on the human health effects of low-level methylmercury exposure. Environ Health Perspect 2012;120:799-806.

9. Koedrith P, Seo YR. Advances in carcinogenic metal toxicity and potential molecular markers. Int J Mol Sci 2011;12:957695 .

10. Pirrone N, Keating T. Hemispheric Transport of Air Pollution, Part B: Mercury. Air Pollution Studies No. 18. Geneva: United Nations; 2010

11. United National Environmental Programme (UNEP). Chemicals, Toolkit for Identification and Quantification of Mercury Releases 2011 [displayed 15 January 2013]. Available at http://www.unep.org/hazardoussubstances/ Portals/9/Mercury/Documents/Publications/Toolkit/ Hg\%20Toolkit-Guideline\%20Level1-Rev-JAN2011.pdf

12. Eco-Bussines. China responsible for $25 \%$ of worldwide mercury emissions 2011 [displayed 15 January 2013]. Available at http://www.eco-business.com/news/chinaresponsible-for-25-of-worldwide-mercury-emissions/

13. Wong CS, Duzgoren-Aydin NS, Aydin A, Wong MH. Sources and trends of environmental mercury emissions in Asia. Sci Total Environ 2006;368:649-62.

14. Li P, Feng XB, Qiu GL, Shang LH, and Li ZG. Mercury pollution in Asia: a review of the contaminated sites. J Hazard Mater 2009;168:591-601.

15. Johnson NC, Manchester S, Sarin L, Gao Y, Kulaots I, Hurt RH. Mercury vapor release from broken compact fluorescent lamps and in situ capture by new nanomaterial sorbents. Environ Sci Technol 2008;42:5772-8.

16. Environment-Agency. Which products do the WEEE regulations apply to? Categories of electrical and electronic equipment 2012 [displayed 15 January 2013]. Available at http://www.environment-agency.gov.uk/business/topics/ waste/32120.aspx

17. U.S. Environmental Protection Agency. Recycling MercuryContaining Light Bulbs (Lamps) 2012 [displayed 15 January 2013]. Available at http://www.epa.gov/waste/hazard/ wastetypes/universal/lamps/index.htm

\section{CORRESPONDING AUTHOR:}

Mohammad Abdollahi

Department of Toxicology and Pharmacology, Faculty of Pharmacy and Pharmaceutical Sciences Research Center, Tehran University of Medical Sciences, Tehran, Iran E-mail:Mohammad@TUMS.Ac.Ir; Mohammad.Abdollahi@UToronto.Ca 